\title{
Near infrared reproduction of images whose originals have dual content
}

\author{
${ }^{1}$ Jana Žiljak, ${ }^{2}$ Denis Jurečić, ${ }^{2}$ Branka Lajić \\ ${ }^{1}$ Zagreb University of Applied Sciences, Zagreb, Croatia \\ ${ }^{2}$ University of Zagreb, Faculty of Graphic Arts, Zagreb, Croatia
}

\begin{abstract}
The painter Nada Žiljak has created two paintings at the same place. The other painting is observed by infrared camera. The oil paintings are done with colorants which absorbe infrared light. The results of new graphical reproductions which include visual and near infrared condition of the original visual act are presented in this paper. The paintig has been reproduced with the print colorants cyan, magenta, yellow and black on the linen. Digital ink-jet print contains double picture for visual and infrared spectrum. The reproduction of artistic painting has the same quality of visualization as it has its original, although these two pictures are dyed with different procedures, different colorants, different pigments, different techniques and different purposes.

The spectral analysis of the light absorption in two areas are acomplished for all colorants: visual and infrared in the range of 400 to $1000 \mathrm{~nm}$. The new algorythms have been developed as well as the programms for computer graphic in order to double mark image on the linen. The linen is used for the dress making which has invisible and hidden security graphic.
\end{abstract}

Keywords - VZ separation, near infrared spectrum, design with NIR colors, INFRARED PAINTING

\section{Introduction}

Inovative solutions are mixing of the painters colorants and their digital simulation in the technology of the conventional print with the aim to realise double image. The hidden information, extended image have been applied on the documents, clothes, the securities and packaging in the practice. The application in digital print is extended to "security print" with process colors and inks. We observe two light areas the first visual area, marked with $\mathrm{V}$, well-known as color area and numerically denoted as 400 to $750 \mathrm{~nm}$ of sun spectrum. The scond area is the first part of near infrared spectrum (NIR) in the range of 800 to $1000 \mathrm{~nm}$, marked as Z [1]. The colorants are studied as digital information in order to develop new algorythms for ink management in the reproduction of image information in two spectral areas. The management of pigmentation in artistic painting and in color reproduction has been developed equally successfully the field of printing tehnology [2].

\section{Colorants for artistic painting in visual and near infrared spectrum}

The painter Nada Žiljak mixes colors to achieve the double painting, "Infrared painting". She divides colorants that do not appear in NIR spectrum. Value Z is added to each colorant which is the information about absorption of light at $1000 \mathrm{~nm}$. The mixture of colors is subordinated to the idea of creation of twin colorant of the same tone but with different component. These twin colors have different response in near infrared spectrum.

Fine art is reaching for the new ways of perception of colors and mixing colors. Painters, graphics and artists in the multimedia field are aware of the possibilities of usage of light qualities beyond the range of the naked eye thus creating new painting.

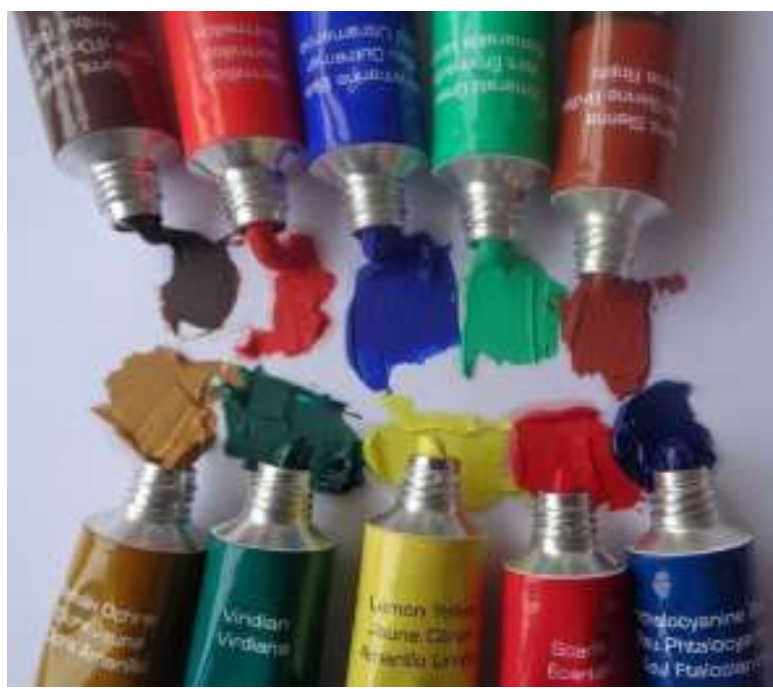

Figure 1. Oil artistic colorants

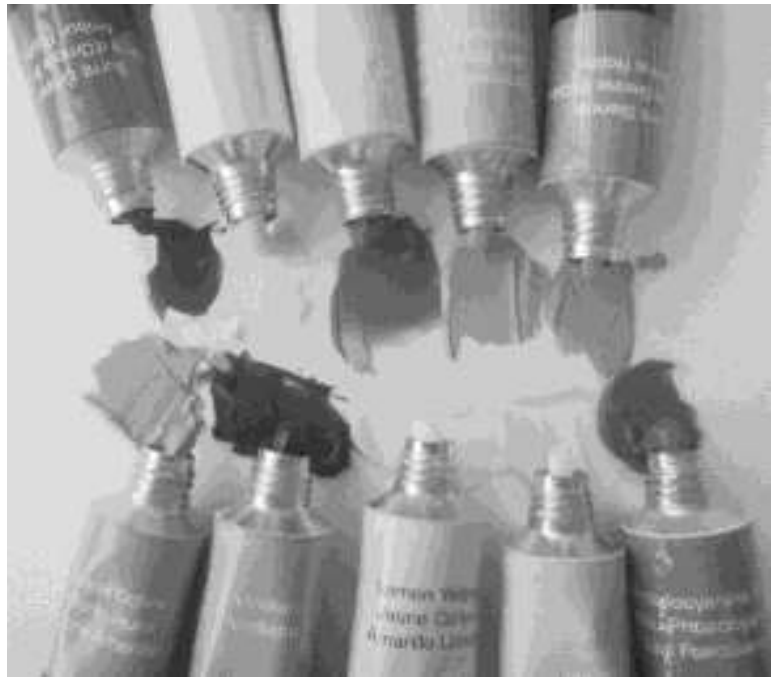

Figure 2. Oil artistic colorants in NIR spectrum 
Colors for artistic painting are photographed by ZRGB camera [3] in visual RGB spectrum and in Z spectrum with blokade at $1000 \mathrm{~nm}$.

TABLE I. NUMERICAL VALUES OF PAINTING COLORS

\begin{tabular}{|l|l|l|l|}
\hline The name of color & RGB & $\mathbf{L} * \mathbf{a} * \mathbf{b}$ & $\mathbf{Z}$ \\
\hline Burnt Umber & $69,63,65$ & $27,3,0$ & 53 \\
\hline Vermillon & $181,45,49$ & $42,55,33$ & 3 \\
\hline Ultramarine blue & $35,42,123$ & $21,20,-48$ & 44 \\
\hline Emerald Green & $77,24,67$ & $52,-41,13$ & 15 \\
\hline Burnt Siena & $121,44,38$ & $30,34,22$ & 19 \\
\hline Yellow Ochre & $159,117,67$ & $53,13,34$ & 22 \\
\hline Virdian & $34,73,70$ & $28,-15,-3$ & 55 \\
\hline Lemon Yellow & $197,191,67$ & $76,-9,60$ & 2 \\
\hline Scarlet & $177,29,41$ & $39,58,34$ & 7 \\
\hline Ohthalocyanone Blue & $27,30,65$ & $13,8,-23$ & 51 \\
\hline
\end{tabular}

This art, the Infrared Painting is extended to the coloring of ceramics, leather, canvas for oil colors, silk and paper. The artists use spectroscopy, something completely new for them, as a tool for achieving hidden, double and invisible image. They use "'Z glasses" specially designed for painters and graphics which enable them to observe the condition of visual act in infrared spectrum as well as watching the image with naked eye. Never before has the artist had the opportunity to create the images of his imagination by hiding his intimate visual act into some other image. Nada Žiljak uses the qualities of light, the quality of colorant matter in a way that opens a new style of expression.

The painting (Fig.3.) was exhibited in Winterthur (Switzerland) at the exhibition called "INFRARED PAINTING" (Kultuzentrum June 14th, 2017.) The surveillanc cameras, with NIR light blockade, were installed at the exhibition room (Fig.5. and Fig.6).

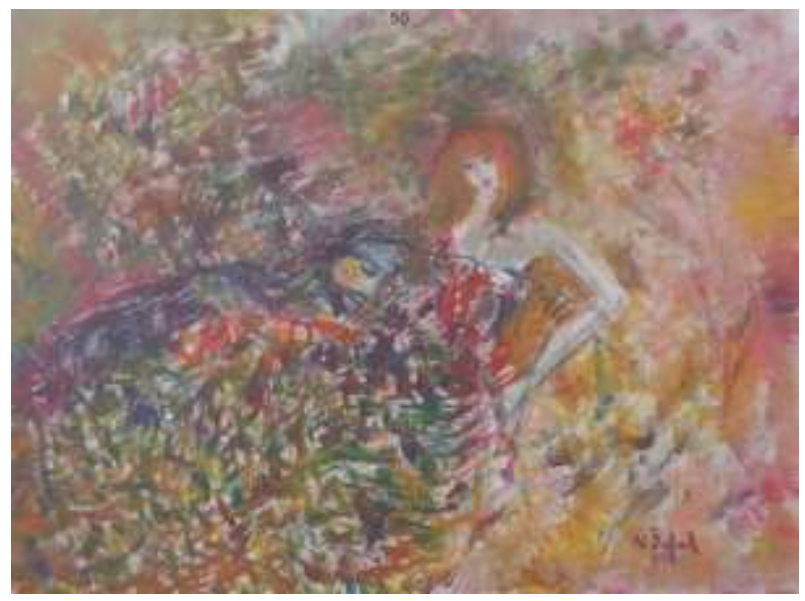

Figure 3. Nada's paining in two spectrums (V visual)

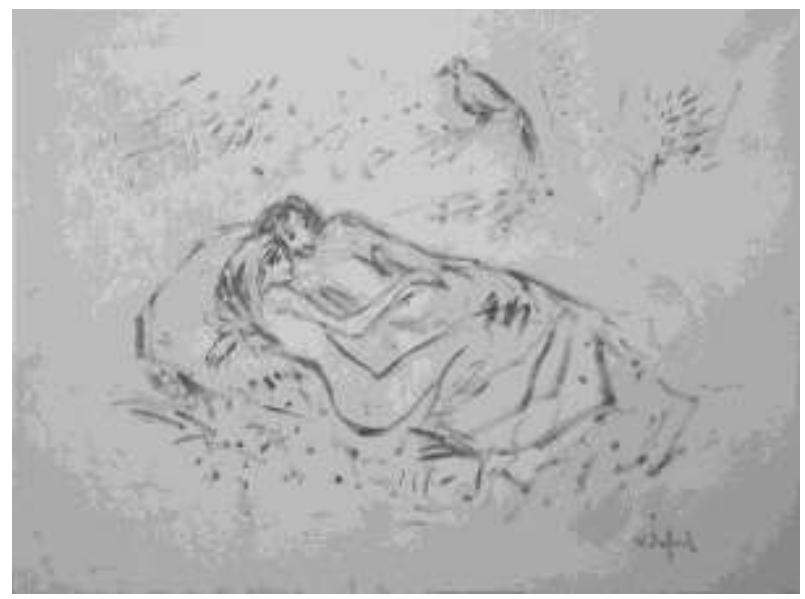

Figure 4. Nada's paining in two spectrums (Z-NIR)

The double state of the painting was photographed with two cameras. The firts camera was positioned in visual $(\mathrm{V})$ RGB (red, green,blue) mode. The second camera wase taking photos in near infrared spectrum (Z-NIR) with blockade at $1000 \mathrm{~nm}$. The situation address of two $\mathrm{V}$ and $\mathrm{Z}$ painting at the exhibition Winterthur (Fig.5. and Fig.6.).

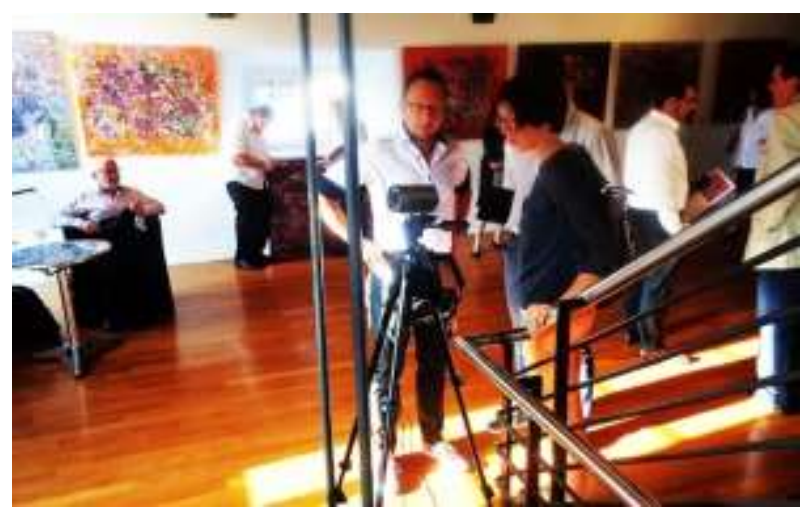

Figure 5. Visitors at the exhibition (visual spectrum)

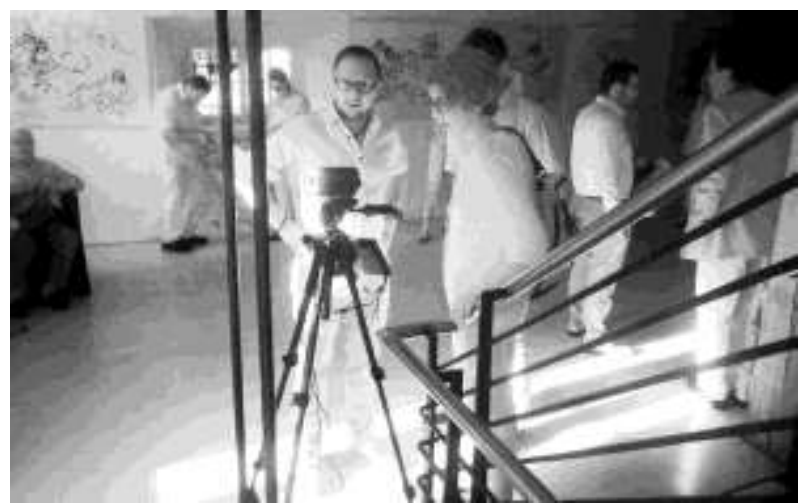

Figure 6. Visitors at the exhibition ( $\mathrm{Z}$ blockade) 


\section{Ink quality for digital print in visual and near infrared spectrum}

Light absorption of the inks shows that $\mathrm{C}, \mathrm{M}, \mathrm{Y}$ inks do not absorb light above $760 \mathrm{~nm}$. Carbon black ink absorbes light in the area where $\mathrm{Z}$ cameras are set up. Mixing of all four inks enables duality of response in some values of light wave lenghts from 400 to $1000 \mathrm{~nm}$ [4]. Algorythms of $\mathrm{VZ}$ separation respect spectrograms in achieving duality in $\mathrm{V}$ (RGB) area, where colors are the same but with different components (CMYK). These colors have different presence in $\mathrm{Z}$ spectrum.

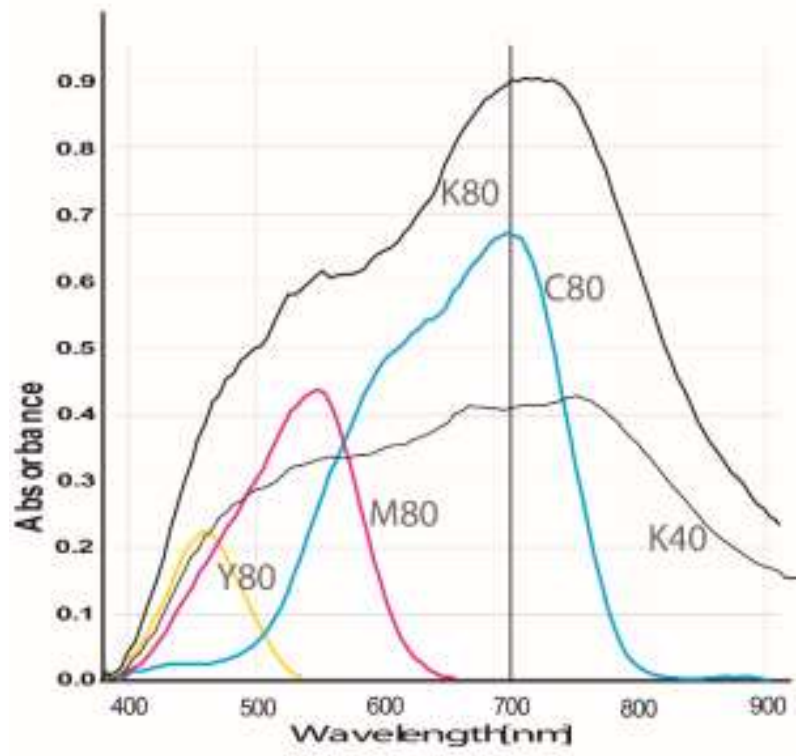

Figure 7. Print colorants CMYK with $80 \%$ coverage

The information of spectral analyses are very important for programming of dual images with colorants from digital print machine. Spectography of colorants and their components is performed with forensic scanner Projektina [5]. Carbon black color is shown in the example of $40 \%$ coverage. This is the basis for print planning on linen for all dye tones. The value of $\mathrm{Z}$ of $18 \%$ is enough for $\mathrm{Z}$ camera to recognize it and divide it from colorants that are not visible above $750 \mathrm{~nm}$ [6].

\section{Inovative dress design with double imaging}

The task for graphic artists is as follows: Create reproduction that has two conditions visual $\mathrm{V}$ and infrared $\mathrm{Z}$, the same as the original act of art painter. "The same" meaning the tolerance we accept like in evaluation of the reproduction of the original painting work. Considering that new INFRARED PAINTING has two conditions of work of art, than we should let the methods of "color management" extend to respective qualities of colorant light absorption in infrared spectrum.

The new reproduction procedure is making possible for the painters to reproduce their new Infrared Art work with the characteristics of invisible, hidden image and at the same time they will have NIR protection of the originality of their art work.

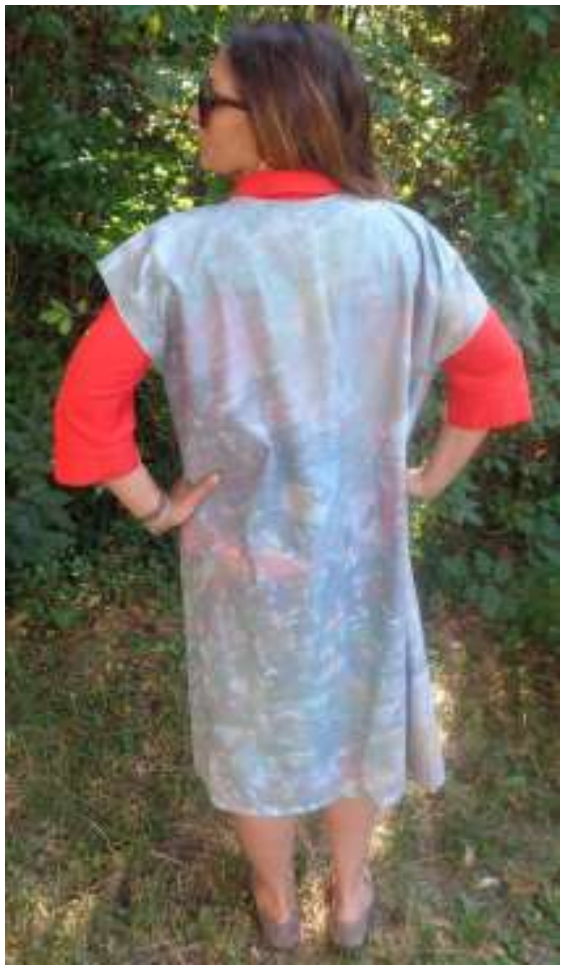

Figure 8. Clothes worn by Jana with Nada's images

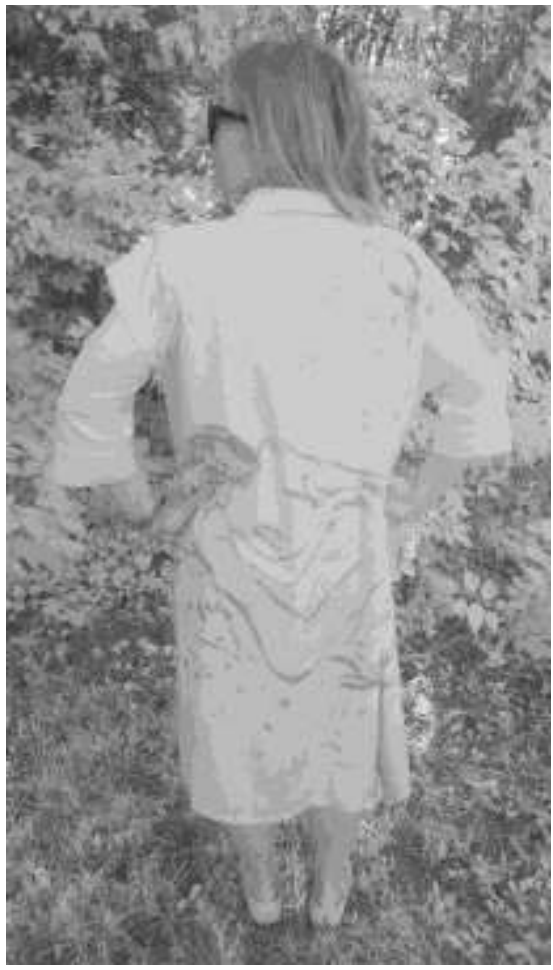

Figure 9. Clothes worn by Jana with Nada's images

We have developed the method of VZ separation which has started with CMYKIR procedure connecting two 
independent pictural information (7). The level of $\mathrm{VZ}$ connection of two pictures is more complex. Both images $\mathrm{V}$ and $\mathrm{Z}$ are situated in the original fine work. The connecting procedure is as follows. Firstly, it is neccessary to exclude, take out, select $\mathrm{Z}$ image from the original act. The visual condition of the image is photographed by equal optical parameters. Considering that there are two cameras, ZRGB cameras, great effort is needed to succeed in matching two images at pixel level. The programmed procedure is developed which includes morphological algorythms. The third step is: Connect two (V and Z) pictures with VZ method of separation as a new example of GCR method of graphic preparation for conventional print with standard process $\mathrm{C}, \mathrm{M}, \mathrm{Y}, \mathrm{K}$ inks. The forth step is: Perform the reproduction as CMYKIR print, where it is necessary to exclude "color management" influence in print software.

The dress is designed according to the painting of artist Nada Žiljak. The gradual transformation of the reproduction of fine work from visual $\mathrm{V}$ condition to $\mathrm{Z}$ condition is shown in continuity by animation. Ten conditions are shot with light blockade which illustrates the appereance and disappereance of individual components of colorants which are inherent to our eye. The original visual work and reproduction of the same one on linen is presented (will be presented) at the Fifth Joint International Conference, 2017. Zurich, Switzerland, useing the double VZ camera.

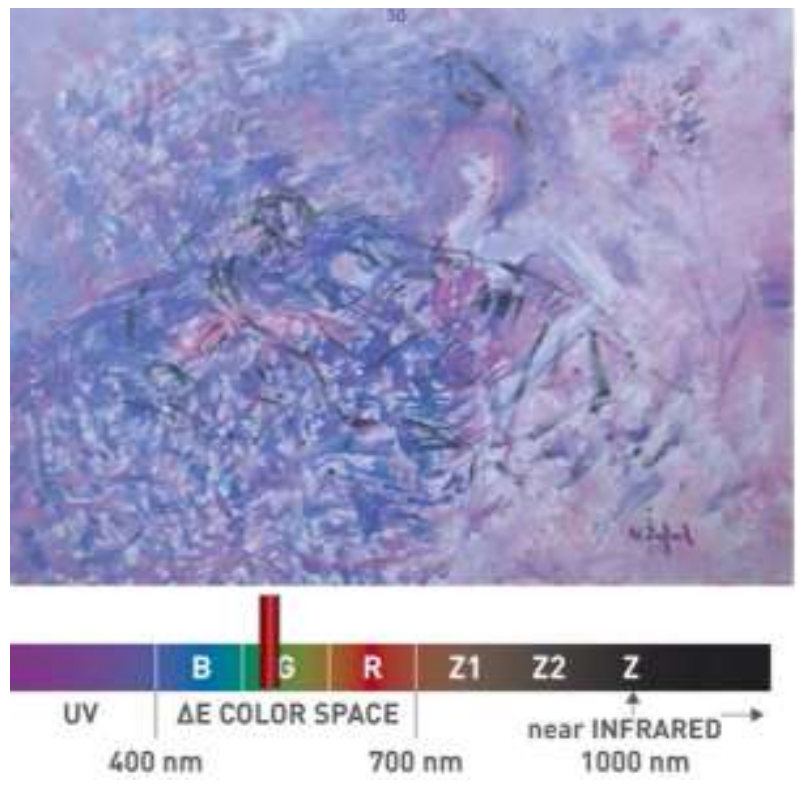

Figure 10. Section cut from animation, lothes with hidden images http://jana.ziljak.hr/Figure10.mp4

Two images are connected with CMYKIR procedure [8]. The improvement of the colorant separation is adjusted to the requirements of the print on the linen [9]. The compensation in yellow color tone is added to the regression model by increasing the values of free parameter in the function of the coverage that color tone. The adjustement of hidding NIR image was defined by experimental plan for print on the digital plotter DURST.
New painting, inventive movement "Infrared painting" uses the knowledge of colorants and their characteristic of light absorption. The painter mixes the colorants with the intention to have two images on the linen for two differnet light blockades. The ultimate intimacy, the extreme message, hidden information, the extreme eroticism will not be seen by the naked eye.

\section{v. Conclusion}

While the painter uses many colors, the digital print is carried out with only four process colors: Cyan, Magenta, Yellow and Black. We announce, here, the new way of colorant separation in printing when the visual original is the double image. The goal is: The reproduction will have the double state. This is the new approach to the technology of "color management", the new mathematical model of the connection of the colorants and materials for the chosen technology of the print on linen.

\section{References}

[1] I. Pogarčić, A. Agić, M. Matas, "EVALUATION OF THE COLORANT TWIN FOR THE NEUTRAL GREY SPECTRA IN INFRARED GRAPHIC PROCEDURE", Technical gazette, 23, 6(2016), 1659-1664 1659; ISSN 1330-3651, ISSN 1848-6339

[2] I. Žiljak Stanimirović, J. Žiljak Vujić, M. Matas, "INFRARED COLORANTS AS TWINS FOR SECURITY PRINTING OF DOCUMENTS AND SECURITIES", 45th Conference of the International Circle of Educational Institutes for Graphic Arts Technology and Management (IC), Toronto, Canada 2013. p. 28-35. ISSN 1868-0712

[3] I. Rajković, V. Žiljak, "Usage of ZRGB video camera as a detection and protection systemand development of invisible infrared design", Polytechnic \& Design ZAGREB UNIVERSITY OF APPLIED SCIENCES; Vol. 4, No. 1, 2016. pp: 54 - 59; ISSN 2459-6302; ISSN 1849-1995; DOI: 10.19279/TVZ.PD.2016-4-1-07

[4] C. Li, C. Wang, S. J. Wang, "A Black Generation Method for Black Ink Hiding Infrared Security Image", Applied Mechanics and Materials, Trans Tech Publications, Switzerland, Vol. 262 (2013), pp. 9-12.

[5] Projectina Docucenter 4500, Switzerland, http://forensictechnology.com/projectina/

[6] V. Žiljak, K. Pap, I. Žiljak-Stanimirović, J. Žiljak-Vujić, "Managing dual color properties with the Z-parameter in the visual and NIR spectrum", Infrared physics \& technology. Vol.55 Issue 4, pp. 326-336; 2012 Elsevier B.V; DOI: 10.1016/j.infrared.2012.02.009

[7] V. Žiljak, K. Pap, I. Žiljak, "CMYKIR SECURITY GRAPHICS SEPARATION IN THE INFRARED AREA", Infrared Physics and Technology Vol.52. No.2-3, ISSN 1350-4495, Elsevier B.V. DOI:10.1016/j.infrared.2009.01.001, p: 62-69, (2009)

[8] M. Friščić, O. Međugorac, L. Tepeš, D. Jurečić, "Invisible information on the transparent polymer food packaging with Infra V/Z technology", Technics Technologies Education Management, Vol 8/4, 2013; P: 1512 1519, ISSN:1840-1503, e-ISSN 1986-809X

[9] V. Žiljak, D. Agić, Anayath Rajendrakumar, "Broadening INFRARED technology on cotton fabric coloration with double information ability in visual and infrared spectra", http://www.ttem.ba; Technics Technologies Education Management, Vol 11/1, 2016, ISSN 1840-1503, e-ISSN 1986-809X p3-10

[10] Authors web site with animation of the absorption of blocked light in spectral from 400 to $1000 \mathrm{~nm}$ : http://jana.ziljak.hr/Figure10.mp4 